\title{
Dopamine cannot promote oligomerization of unoxidized $\alpha$-synuclein
}

\author{
Sakurako Shimotakahara ${ }^{1}$, Mika Matsui ${ }^{1}$, Chiseko Sakuma $^{1}$, Teruaki Takahashi $^{1}$, \\ Takashi Fujimoto $^{2}$, Kazuo Furihata ${ }^{3}$, Masaki Kojima ${ }^{4}$, Shohei Seino ${ }^{4}$, Tomoya Machinami ${ }^{2}$, \\ Yoichi Shibusawa ${ }^{1}, K_{\text {Kenji Uéda }}{ }^{5}$, Mitsuru Tashiro ${ }^{2^{\star}}$ \\ ${ }^{1}$ School of Pharmacy, Tokyo University of Pharmacy and Life Sciences, Tokyo, Japan \\ ${ }^{2}$ Department of Chemistry, School of Sciences and Engineering, Meisei University, Tokyo, Japan; \\ *Corresponding Author: tashiro@chem.meisei-u.ac.jp \\ ${ }^{3}$ Division of Agriculture and Agricultural Life Sciences, The University of Tokyo, Tokyo, Japan \\ ${ }^{4}$ School of Life Science, Tokyo University of Pharmacy and Life Science, Tokyo, Japan \\ ${ }^{5}$ Department of Dementia and Higher Brain Function, Tokyo Metropolitan Institute of Medical Science, Tokyo, Japan
}

Received 4 June 2013; revised 4 July 2013; accepted 12 July 2013

Copyright (C) 2013 Sakurako Shimotakahara et al. This is an open access article distributed under the Creative Commons Attribution License, which permits unrestricted use, distribution, and reproduction in any medium, provided the original work is properly cited.

\begin{abstract}
$\alpha$-Synuclein is the major component of the filamentous Lewy bodies and Lewy neurites that define neuropathological features of Parkinson's disease and dementia with Lewy bodies. To investigate the oligomerization process of $\alpha$-synuclein in association with dopamine (DA), the structural propensities to form oligomers were studied using NMR and other biophysical techniques. The ${ }^{1} \mathrm{H}^{15} \mathrm{~N}$ HSQC spectra indicated that both $\mathrm{N}$ - and C-termini interacted with DA. Although interactions with DA were also observed in the presence of glutathione by ESI-MS, the significant suppression of oligomerization was observed in the size exclusion chromatography, suggesting that oxidations of $\alpha$-synuclein are required for its oligomerization.
\end{abstract}

Keywords: $\alpha$-Synuclein; Dopamine; Glutathione; Oligomerization

\section{INTRODUCTION}

$\alpha$-Synuclein is a 140 -amino acid protein characterized by an acidic C-terminal region and seven imperfect repeats (consensus KTKEGV) distributed throughout most of the N-terminal half of the polypeptide [1]. $\alpha$-Synuclein is a highly soluble, heat-stable and natively unfolded protein $[2,3]$ predominantly expressed in the neurons of the central nervous system. It is localized at presynaptic terminals in close proximity to synaptic vesicles $[1$, 4-6], as well as in the neuronal nuclei [7]. Recently, in- teractions between $\alpha$-synuclein and dopamine (DA) have been vigorously studied [8-12]. These studies suggest that distinctly reactive intermediates of $\alpha$-synuclein interacting with DA induce its oligomerization [10]. Although it has been proposed that the formation of DA-interacting $\alpha$-synuclein provides an explanation for the dopaminergic pathway of $\alpha$-synuclein-associated neurotoxicity in PD [8], the details of interactions between $\alpha$-synuclein and DA are yet to be elucidated. Our group has been engaged in the study of fibrillation and oligomerization processes of $\alpha$-synuclein at the initial stage. The singular value decomposition analysis using the timedependent $C D$ spectra revealed that five or nine intermediates were formed at the early stage of fibrillation [13]. In the time-dependent small angle $\mathrm{X}$-ray scattering (SAXS) measurements, formation of oligomers comprising heptamer was suggested [14]. Interactions between $\alpha$-synuclein and DA were studied using an electrospray ionization mass spectrometry (ESI-MS) and the size exclusion chromatography. The results indicated that three DAs bound to an intact $\alpha$-synuclein and oligomerizaton was induced in the presence of DA [15]. In purpose to investigate the oligomer association mechanism of $\alpha$-synuclein, interactions between $\alpha$-synuclein and DA have been studied using NMR spectroscopy and other biophysical techniques. Effects of glutathione (GSH), which is antioxidant, have also been studied to investigate propensities of $\alpha$-synuclein to form oligomers. Because DA is considered to be one of the critical factors in aggregation or oligomerization, elucidation of $\alpha$-synuclein oligomerization with DA is expected to provide valuable clues for the molecular mechanism of PD. 


\section{MATERIALS AND METHODS}

\subsection{Expression and Purification of $\alpha$-Synuclein}

Recombinant $\alpha$-synuclein was expressed in E. coli BL21 (DE3) (Novagen) grown at $37^{\circ} \mathrm{C}$ in $\mathrm{M} 9$ medium using the expression vector pET15b (Novagen) and purified as described previously [13]. The ${ }^{15} \mathrm{~N}$-labled $\alpha$-synuclein was expressed using ${ }^{15} \mathrm{NH}_{4} \mathrm{Cl}$ as a nitrogen source. The solutions of $0.2 \mathrm{mM} \alpha$-synuclein containing $1.0 \mathrm{mM}$ DA were assembled into oligomers in the absence and presence of $1.0 \mathrm{mM}$ GSH by incubating in10 $\mathrm{mM}$ ammonium acetate $(\mathrm{pH} 7.5)$ at $30^{\circ} \mathrm{C}$ with continuous stirring at $450 \mathrm{rpm}$. These solutions were used in analysis of ESI-MS and size exclusion chromatography.

\subsection{NMR Spectroscopy}

The $2 \mathrm{D}{ }^{1} \mathrm{H}^{15} \mathrm{~N}$ HSQC spectra were recorded using sample solutions of, 1) $0.2 \mathrm{mM}^{15} \mathrm{~N}$-labeled $\alpha$-synuclein and 1.0 $\mathrm{mM} \mathrm{DA}$; and 2) $0.2 \mathrm{mM}^{15} \mathrm{~N}$-labeled $\alpha$-synuclein, $1.0 \mathrm{mM}$ DA and $1.0 \mathrm{mM} \mathrm{GSH}$ at the incubation time of 0 , 24 and $72 \mathrm{~h}$ on a Bruker DRX-500 spectrometer. All HSQC spectra were acquired at $4^{\circ} \mathrm{C}$ using the identical receiver gain. The experimental parameters used for the $2 \mathrm{D}{ }^{1} \mathrm{H}-{ }^{15} \mathrm{~N}$ HSQC were: data size in $t_{1}=128$ complex points; data size in $t_{2}=1024$; spectral width in $f_{1}=2048$ $\mathrm{Hz}$; spectral width in $f_{2}=6000 \mathrm{~Hz}$; number of transients per increment $=16$. The WATERGATE W5 LOGSY [16] spectra were recorded using a solution of $0.1 \mathrm{mM} \alpha$ synuclein in the presence of $8.0 \mathrm{mM} \mathrm{DA}$ and/or $8.0 \mathrm{mM}$ $\mathrm{GSH}$ at $20^{\circ} \mathrm{C}$ on a Varian Inova 500 spectrometer. The experimental parameters used for the WATERGATE W5 LOGSY were: data size $=8192$ points; spectral width $=$ $10,000 \mathrm{~Hz}$; number of scans $=64$.

\subsection{MS Spectrometry}

ESI-MS measurements were carried out using a time-of-flight mass spectrometer (JEOL JMS-T100). The experimental conditions were as follows: acceleration voltage, $2.0 \mathrm{kV}$; needle voltage, $2600 \mathrm{~V}$; orifice voltage, $65 \mathrm{~V}$; desolvation temperature, $100^{\circ} \mathrm{C}$; sample flow rate, $5.0 \mu \mathrm{L} / \mathrm{min}$. All spectra were obtained via infusion of the sample solutions in the positive ionization mode.

\subsection{Size Exclusion Chromatography}

The incubated sample solutions were filtrated through a membrane filter Dismic-03 (pore size, $0.45 \mu \mathrm{m}$; Toyo Roshi), and then applied onto a TSKgel G3000SW $\mathrm{XL}_{\mathrm{XL}}$ gel filtration column $(7.8 \mathrm{~mm}$ I.D. $\times 300 \mathrm{~mm}$; Tosoh Bioscience) with $50 \mathrm{mM}$ sodium phosphate buffer, $\mathrm{pH} 7.5$, containing $100 \mathrm{mM} \mathrm{NaCl}$. The flow rate was $0.4 \mathrm{~mL} /$ $\min$.

\section{RESULTS AND DISCUSSION}

\subsection{Observation of Interactions between $\alpha$-Synuclein and Dopamine by NMR Spectroscopy and MS Spectrometry}

In observation of interactions between $\alpha$-synuclein and DA at the atomic level, the $2 \mathrm{D}{ }^{1} \mathrm{H}-{ }^{15} \mathrm{~N}$ HSQC spectra were acquired using the ${ }^{15} \mathrm{~N}$-labeled $\alpha$-synuclein in the presence of DA (Figure 1). The expanded spectra, indicating the chemical shift changes of L8, S9 and S129, are shown in Figure 2. The chemical shift changes were identified for the residues of V3, L8, S9, A27, H50, N113, D119, E126, M127 and S129, which are considered to interact with DA. In the presence of GSH, the chemical shift changes were identified for the residues of V3, L8, A27, N113, D119, E126, M127 and S129 (data not shown). Any chemical shift changes of $\alpha$-synuclein were not identified only in the presence of GSH (data not shown). These results indicate that $\mathrm{N}$-terminal and $\mathrm{C}$ terminal regions of $\alpha$-synucleinare involved in the inter-

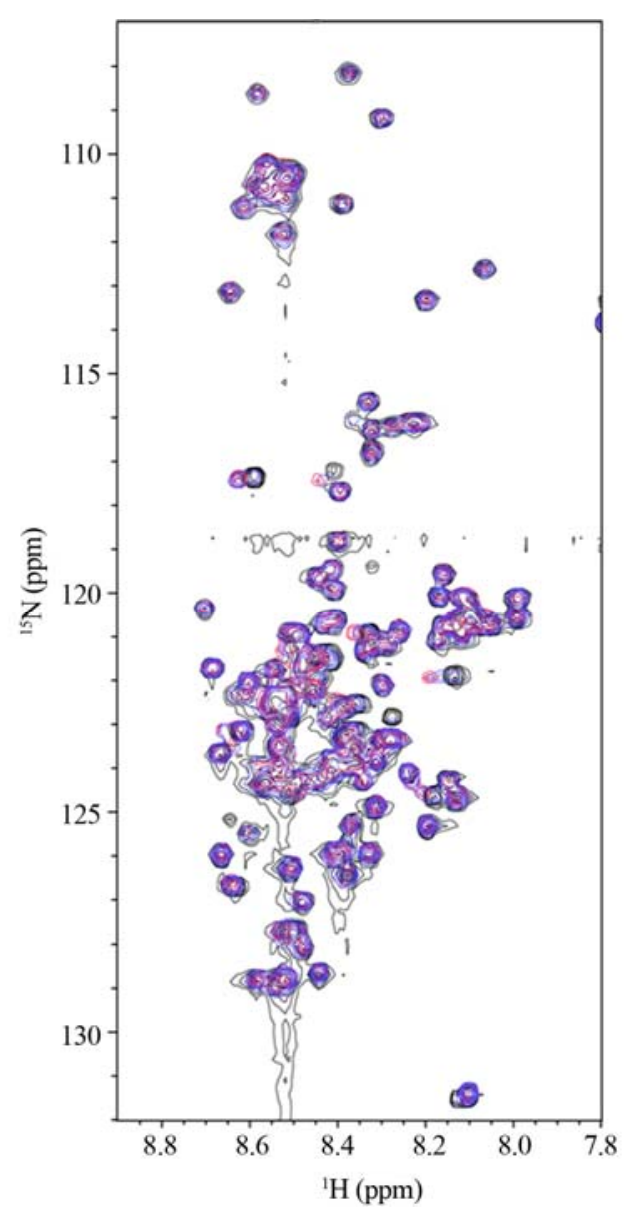

Figure 1. The $2 \mathrm{D}^{1} \mathrm{H}-{ }^{15} \mathrm{~N}$ HSQC spectra of 0.2 $\mathrm{mM}^{15} \mathrm{~N}$-labeled $\alpha$-synuclein in the presence of $1.0 \mathrm{mM}$ DA at incubation times of 0 (black), 24 (blue) and 72 (red) hours. 

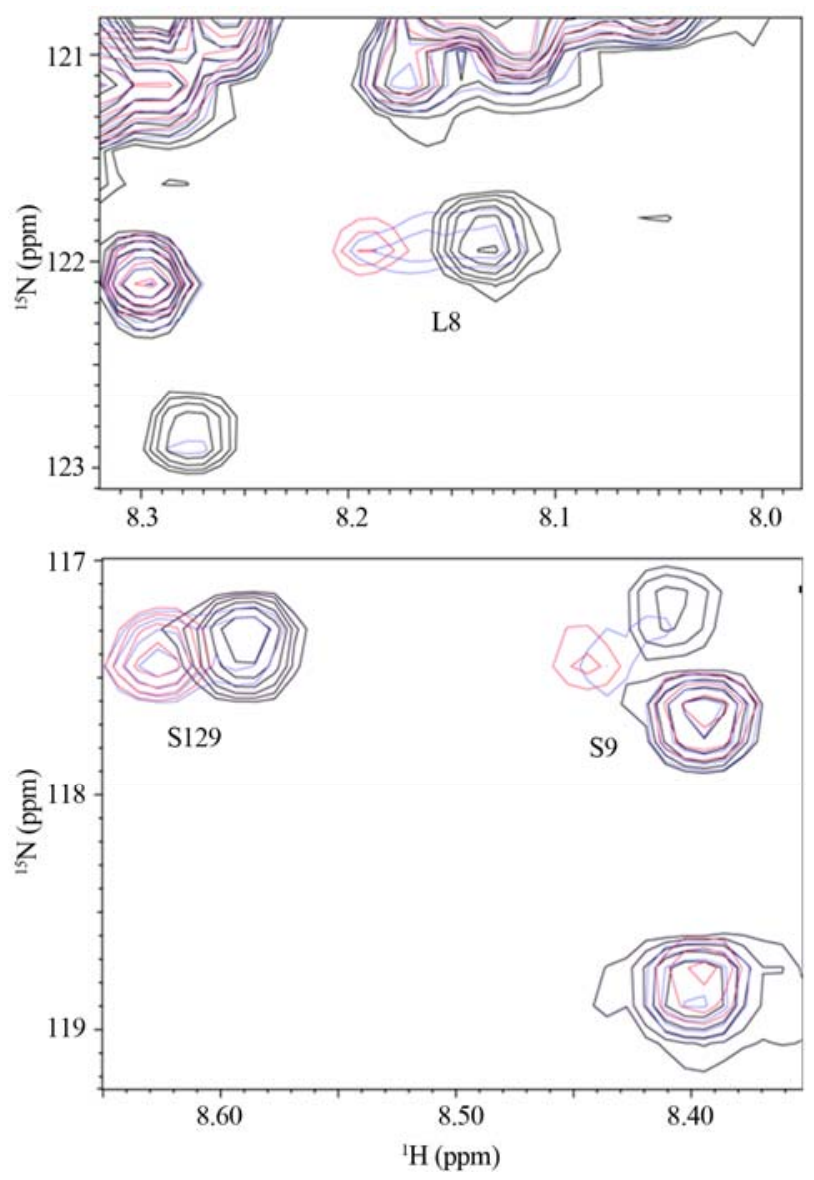

Figure 2. The expanded spectra of Figure 1. The chemical shift changes of (a) L8 and (b) S9 and S129 are shown.

actions with DA, and that GSH is not involved. Because the oligomer formation of $\alpha$-synuclein was distinctly induced upon binding with DA $[10,15]$, both $\mathrm{N}$ - and C-termini are considered to play a key role in oligomerization. An importance of C-terminal in aggregation of $\alpha$-synuclein was demonstrated by Mazzulli, et al., using the protein lacking the polypeptide segment ${ }^{125}$ YEMPS $^{129}$ [17]. It was shown that the intracellular inhibition of $\alpha$-synuclein aggregation required the specific noncovalent interaction of the oxidized catechols with the residues ${ }^{125}$ YEMPS $^{129}$. On the other hand, another study demonstrated that a truncated $\alpha$-synuclein mutant terminating at residue 124 could still form soluble oligomers in the presence of DA, and that mutagenesis of all four Met residues to Ala significantly reduced the propensity to form oligomers $[18,19]$. In the present chemical shift perturbation study using the ${ }^{1} \mathrm{H}-{ }^{15} \mathrm{~N}$ HSQC spectra, three residues, E126, M127 and S129, were involved in the polypeptide segment ${ }^{125}$ YEMPS $^{129}$ in the C-terminal region. Since two of four Met residues are positioned in the $\mathrm{N}$-terminal region, the present results suggested that both $\mathrm{N}$ - and $\mathrm{C}$-terminal regions are required in oligomerization.
Interactions of $\alpha$-synuclein with DA in the presence and absence of GSH were also observed using the WATERGATE W5 LOGSY as shown in Figure 3. In this NMR method, the small molecules which bind to protein can be selectively detected, and the unbound small molecules are observed in the opposite phase. The ${ }^{1} \mathrm{H}$ signals of DA were selectively observed as expected (Figure 3(a)), and interactions of GSH with $\alpha$-synuclein could not be identified as shown in Figure 3(b). It was shown that DA was able to bind with $\alpha$-synuclein in the presence of GSH (Figure 3(c)), indicating that the unoxidized $\alpha$-synuclein had an ability to bind with DA. The above interactions were also observed by ESI-MS. Envelopes of ions between $\mathrm{m} / \mathrm{z} 852$ and 2412, corresponding to +17 through +6 charged states of monomers, were observed (data not shown). The expanded spectra between $\mathrm{m} / \mathrm{z} 1420$ and 1570 are shown in Figure 4. The envelopes of ion peaks between $\mathrm{m} / z 1447$ and 1450 corresponded to the monomeric $\alpha$-synuclein $(m w=14460)$ with +10 charged state. In this envelope, the ion peaks consisted of the free $\alpha$-synuclein and its sodium adducts. In the presence of DA $(m w=153)$, the ion peaks corresponding to the complexes of $\alpha$-synuclein and DA were observed (Figure 4(a)). The maximum of two DA molecules were detected to bind with one molecule of $\alpha$-synuclein even in the presence of GSH (Figure 4(b)). The ion peaks of the complexes comprising $\alpha$-synuclein and DA were observed by ESI-MS, and ${ }^{1} \mathrm{H}$ signals of DA bound to $\alpha$-synuclein were selectively observed by NMR spectroscopy. These results indicate a distinct interaction of DA with theunoxidized $\alpha$-synuclein.

\subsection{Suppression of Oligomer Formation by Glutathione}

The effects of GSH in oligomerization of $\alpha$-synuclein in the presence of DA were monitored using size exclusion chromatography as shown in Figure 5. In the chromatograms of $\alpha$-synuclein, the monomerwas eluted at 24 minutes. Several high molecular weight oligomers with retention times from ca. $17 \mathrm{~min}$ to 23 min were observed in the presence of $1 \mathrm{mM}$ DA at 24, 72 and 120 hour incubations (Figure 5(a)). Distribution of the molecular weights was estimated to be in the range of ca. $65-150$ $\mathrm{kDa}$ based on the calibration curve provided by Tosoh Bioscience. Observation of the high molecular weight species indicates formation of the DA-induced oligomers. Interestingly, any formation of oligomers could not be observed in the presence of $1 \mathrm{mM} \mathrm{GSH}$ (Figure 5(b)). Although the results of NMR and ESI-MS indicated that DA had an affinity with $\alpha$-synuclein in the presence of $\mathrm{GSH}$, the result of size exclusion chromatography demonstrated the distinct suppression of oligomerization under the anti-oxidant condition. These results suggest that an association with DA could be a trigger of oligomeri- 


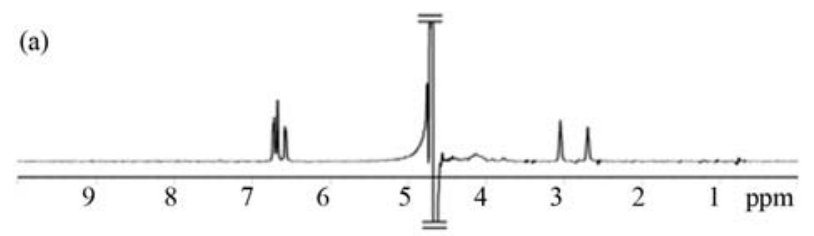

(b)

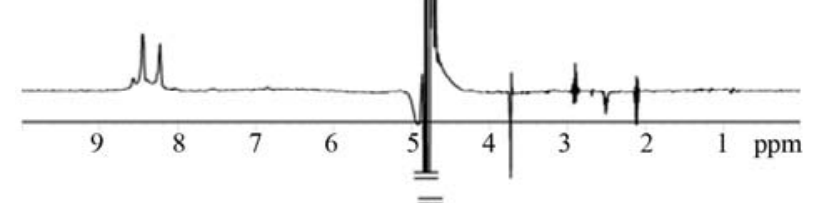

(c)

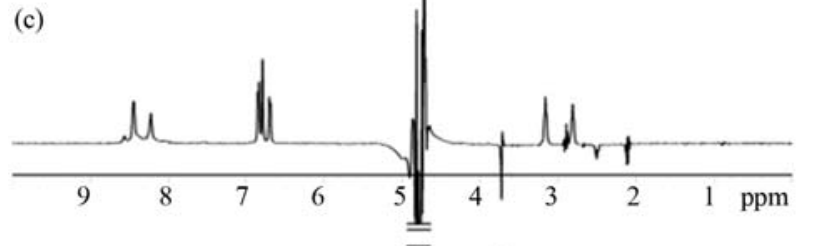

(d)

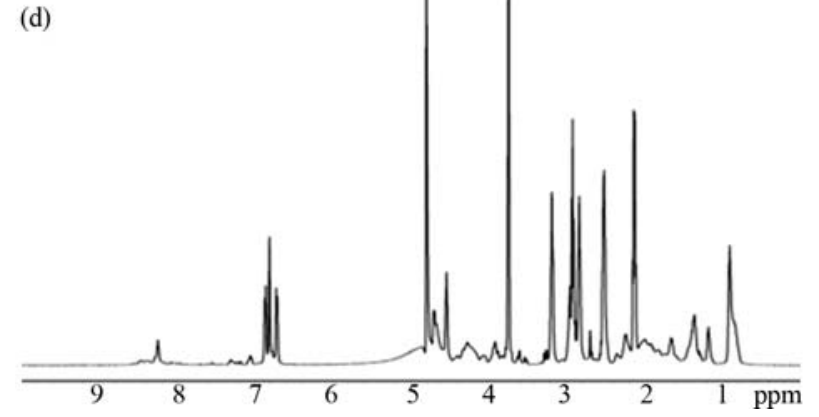

Figure 3. The WATERGATE W5 LOGSY spectra of (a) 0.1 $\mathrm{mM} \alpha$-synuclein in the presence of $8.0 \mathrm{mM} \mathrm{DA}$, (b) $0.1 \mathrm{mM}$ $\alpha$-synuclein in the presence of $8.0 \mathrm{mM} \mathrm{GSH}$, (c) $0.1 \mathrm{mM}$ $\alpha$-synuclein in the presence of $8.0 \mathrm{mM}$ DA and $8.0 \mathrm{mM} \mathrm{GSH}$. (d) The reference spectrum of (c) acquired by presaturation.

zation, and some oxidations of $\alpha$-synuclein are required to proceed with oligomerization. The observations of oligomers comprising $\alpha$-synuclein with four oxidized Met [9-11] coincide with the present results of size exclusion chromatography. In $\gamma$-synuclein, which is another member of the synuclein family, M38 and Y39 can be easily oxidized and $\gamma$-synuclein can form annular oligomers that accumulate in cells [20]. Its oxidation plays a key role in the ability of $\gamma$-synuclein to aggregate and seed the aggregation of $\alpha$-synuclein. Oxidation of the synuclein family could induce a cascade of events leading to synucleinopathies.

\section{CONCLUSION}

In the present study, propensities to form oligomers of $\alpha$-synuclein were studied using NMR, ESI-MS and size (a)

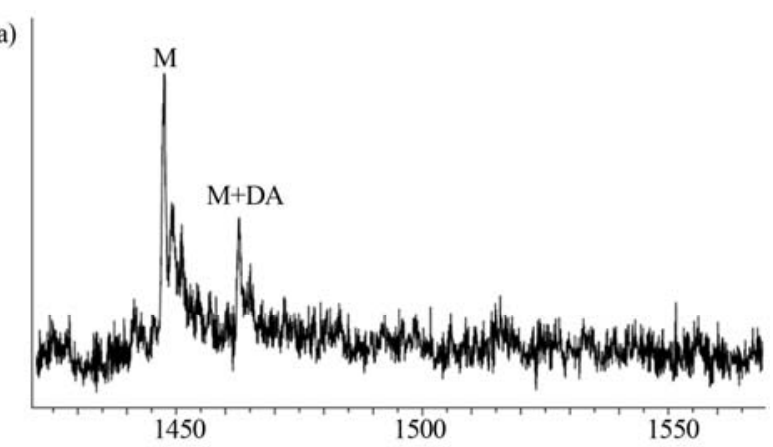

(b)

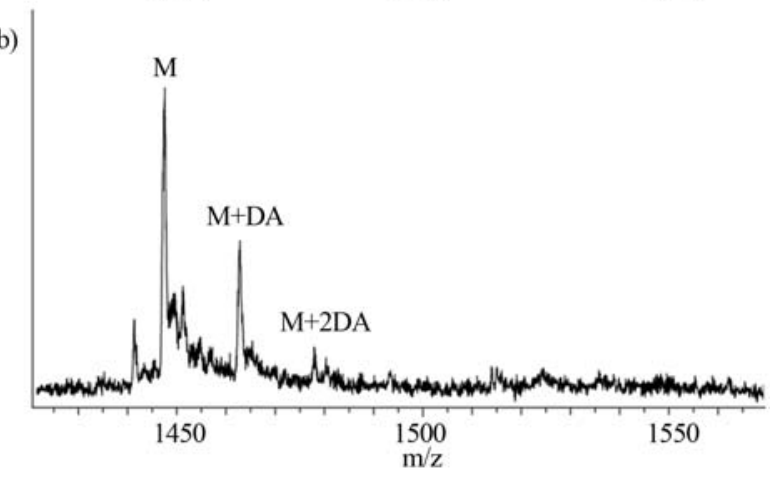

Figure 4. ESI-MS spectra of (a) $0.2 \mathrm{mM} \alpha$-synuclein in the presence of $1.0 \mathrm{mM} \mathrm{DA}$ and (b) $0.2 \mathrm{mM} \alpha$-synuclein in the presence of $1.0 \mathrm{mM}$ DA and $1.0 \mathrm{mM} \mathrm{GSH}$.
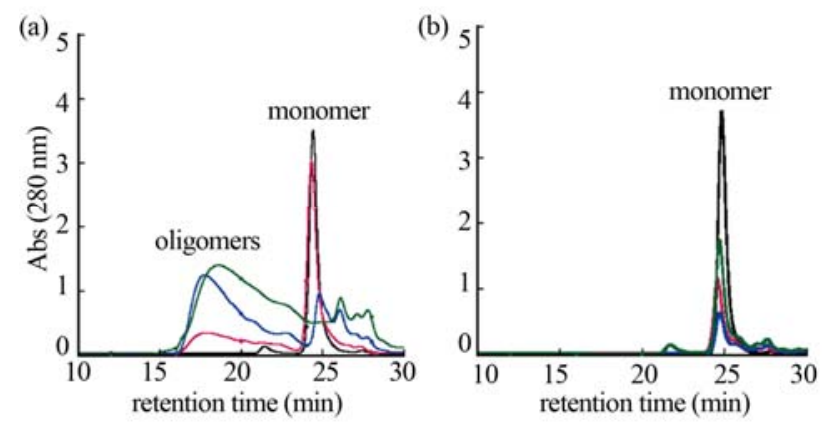

Figure 5. Size exclusion chromatography of (a) $0.2 \mathrm{mM}$ $\alpha$-synuclein in the presence of $1.0 \mathrm{mM} \mathrm{DA}$ and (b) $0.2 \mathrm{mM}$ $\alpha$-synuclein in the presence of $1.0 \mathrm{mM} \mathrm{DA}$ and $1.0 \mathrm{mM} \mathrm{GSH}$ at incubation times of 0 (black), 24 (red), 72 (blue) and 120 (green) hours. The peaks of monomer and oligomers are labeled.

exclusion chromatography. In the analysis using size exclusion chromatography, it was shown that oligomer formations were suppressed under the anti-oxidant condition. Although $\alpha$-synuclein interacted with DA in the presence of GSH, it was suggested that oxidation of $\alpha$-synuclein is required as the further step to accomplish the oligomer formation.

\section{ACKNOWLEDGEMENTS}

This study was supported by a Grant-in-Aid for Scientific Research (No. 17550085 for S.S and 24550108 for M.T.) from the Ministry of 
Education, Culture, Sports, Science, and Technology.

\section{REFERENCES}

[1] Uéda, K., Fukushima, H., Masliah, E., Xia, Y., Iwai, A., Yoshimoto, M., Otero, D.A., Kondo, J., Ihara, Y. and Saitoh, T. (1993) Molecular cloning of cDNA encoding an unrecognized component of amyloid in Alzheimer disease. Proceedings of the National Academy of Sciences of USA, 90, 11282-11286. doi:10.1073/pnas.90.23.11282

[2] Weinreb, P.H., Zhen, W., Poon, A.W., Conway, K.A. and Lansbury, P.T. (1996) NACP, a protein implicated in Alzheimer's disease and learning, is natively unfolded. Biochemistry, 35, 13709-13715. doi:10.1021/bi961799n

[3] Davidson, W.S., Jonas, A., Clayton, D.F. and George, J.M. (1998) Stabilization of $\alpha$-synuclein secondary structure upon binding to synthetic membranes. The Journal of Biological Chemistry, 273, 9443-9449. doi:10.1074/jbc.273.16.9443

[4] George, J.M., Jin, H., Woods, W.S. and Clayton, D.F. (1995) Characterization of a novel protein regulated during the critical period for song learning in the zebra finch. Neuron, 15, 361-372. doi:10.1016/0896-6273(95)90040-3

[5] Iwai, A., Masliah, E., Yoshimoto, M., Ge, N., Flanagan, L., De Silva, H.A., Kittel, A. and Saitoh, T. (1995) The precursor protein of non-A beta component of Alzheimer's disease amyloid is a presynaptic protein of the central nervous system. Neuron, 14, 467-475. doi:10.1016/0896-6273(95)90302-X

[6] Ma, Q.L., Chan, P., Yoshii, M. and Uéda, K. (2003) Alpha-synuclein aggregation and neurodegenerative diseases. Journal of Alzheimer's Disease, 5, 139-148.

[7] Yu, S., Li, X., Liu, G., Han, J., Zhang, C., Li, Y., Xu, S., Liu, C., Gao, Y., Yang, H., Uéda, K. and Chan, P. (2007) Extensive nuclear localization of alpha-synuclein in normal rat brain neurons revealed by a novel monoclonal antibody. Neuroscience, 145, 539-555.

doi:10.1016/j.neuroscience.2006.12.028

[8] Conway, K.A., Rochet, J.C., Bieganski, R.M. and Lansbury, P.T. Jr. (2001) Kinetic stabilization of the alpha-synucleinprotofibril by a dopamine-alpha-synuclein adduct. Science, 294, 1346-1349.

doi:10.1126/science.1063522

[9] Pham, C.L.L., Leong, S.L., Ali, F.E., Kenche, V.B., Hill, A.F., Gras, S.L., Barnham, K.J. and Cappai, R. (2009) Dopamine and the dopamine oxidation product 5,6-dihydroxylindole promote distinct on-pathway and off-pathway aggregation of alpha-synuclein in a $\mathrm{pH}$-dependent manner. Journal of Molecular Biology, 387, 771-785. doi:10.1016/j.jmb.2009.02.007

[10] Rekas, A., Knott, R.B., Sokolova, A., Barnham, K.J., Perez, K.A., Masters, C.L., Drew, S.C., Cappai, R., Curtain, C.C. and Pham, C.L.L. (2010) The structure of dopamine induced $\alpha$-synuclein oligomers. European Bio- physics Journal, 39, 1407-1419. doi:10.1007/s00249-010-0595-x

[11] Bisaglia, M., Tosatto, L., Munari, F., Tessari, I., de Laureto, P.P., Mammi, S. and Bubacco, L. (2010) Dopamine quinones interact with $\alpha$-synuclein to form unstructured adducts. Biochemical and Biophysical Research Communications, 394, 424-428. doi:10.1016/j.bbrc.2010.03.044

[12] Lee, H.J., Baek, S.M., Ho, D.H., Suk, J.E., Cho, E.D. and Lee, S.J. (2011) Dopamine promotes formation and secretion of non-fibrillar alpha-synuclein oligomers. Experimental and Molecular Medicine, 43, 216-222. doi:10.3858/emm.2011.43.4.026

[13] Kamiyoshihara, T., Kojima, M., Uéda, K., Tashiro, M. and Shimotakahara, S. (2007) Observation of multiple intermediates in $\alpha$-synuclein fibril formation by singular value decomposition analysis. Biochemical and Biophysical Research Communications, 355, 398-403. doi:10.1016/j.bbrc.2007.01.162

[14] Tashiro, M., Kojima, M., Kihara, H., Kasai, K., Kamiyoshihara, T., Uéda, K. and Shimotakahara, S. (2008) Characterization of fibrillation process of $\alpha$-synuclein at the initial stage. Biochemical and Biophysical Research Communications, 369, 910-914. doi:10.1016/j.bbrc.2008.02.127

[15] Shimotakahara, S., Shiroyama, Y., Fujimoto, T., Akai, M., Onoue, T., Seki, H., Kado, S., Machinami, T., Shibusawa, Y., Uéda, K. and Tashiro, M. (2012) Demonstration of three dopamine molecules bound to $\alpha$-synuclein: Implication of oligomerization at the initial stage. Journal of Biophysical Chemistry, 3, 149-155. doi:10.4236/jbpc.2012.32017

[16] Furihata, K., Shimotakahara, S. and Tashiro, M. (2008) An efficient use of the WATERGATE W5 sequence for observing a ligand binding with a protein receptor. Magnetic Resonance in Chemistry, 46, 799-802. doi: $10.1002 / \mathrm{mrc} .2264$

[17] Mazzulli, J.R., Armakola, M., Dumoulin, M., Parastatidis, I. and Ischiropoulos, H. (2007) Cellular oligomerization of alpha-synuclein is determined by the interaction of oxidized catechols with a C-terminal sequence. The Journal of Biological Chemistry, 282, 31621-31630. doi:10.1074/jbc.M704737200

[18] Leong, S.L., Cappaim, R., Barnhamm, K.J. and Pham, C.L. Modulation of alpha-synuclein aggregation by dopamine: A review. (2009) Neurochemical Research, 34, 1838-1846. doi:10.1007/s11064-009-9986-8

[19] Leong, S.L, Pham, C.L., Galatis, D., Fodero-Tavoletti, M.T., Perez, K., Hill, A.F., Masters, C.L., Ali, F.E., Barnham, K.J. andCappai, R. (2009) Formation of dopaminemediated alpha-synuclein-soluble oligomers requires methionine oxidation. Free Radical Biology \& Medicine, 46, 1328-1337. doi:10.1016/j.freeradbiomed.2009.02.009

[20] Surgucheva, I., Sharov, V.S., Surguchov, A, (2012) $\gamma$-Synuclein: Seeding of $\alpha$-synuclein aggregation and transmission between cells. Biochemsiry, 51, 4743-4754. doi:10.1021/bi300478w 